\title{
INTERNATIONALIZATION OF SLOVAK FAMILY ENTERPRISES - TERRITORIAL APPROACH
}

\author{
Ladislav Mura \\ Faculty of Economics and Business, Pan-European University in Bratislava, Slovak Republic \\ Email: ladislav.mura@gmail.com
}

Received: 04. September 2021. Revision received: 22. November 2021. Accepted: 10. December 2021

\begin{abstract}
Entrepreneurial activity is currently confronted with a large number of different influences, which affect the performance of business units. Businesses face new situations due to the changing market conditions they have to respond to. The small and medium-sized business sector responds dynamically as well as very sensitively to market changes, where many family businesses are also established. Competition between market players forces both the management and the family businesses to think about new opportunities in order to ensure their growth. As a result, small and medium-sized businesses gain increased importance in international markets. This study aims to identify the current trend in the international activity of family businesses in terms of their territorial activity. In addition to the theoretical background, the submitted study also introduces the results of our empirical survey. The questionnaire survey was applied as an appropriate research method. We decided to apply a dual approach: qualitative (mainly for the theoretical part) and quantitative for the empirical part of the study. The obtained results show family businesses' interest in operating in the international business environment.
\end{abstract}

KEYWORDS: international entrepreneurship, international business environment, internationalisation, Slovak family enterprises

JEL CLASSIFICATION: B27, L21, L26, M16

Reference: Mura, L., (2021). Internationalization of Slovak family enterprises - territorial approach. International Journal of Entrepreneurial Knowledge, 9(2), 109-118. doi: 10.37335/ijek.v9i2.147

\section{INTRODUCTION}

The basic characteristic of business units in the market economy is conducting business activity. Entrepreneurship is becoming an essential attribute and a developmental and driving force of marketoriented economies. Market players aim primarily to achieve economic and financial growth, ensure economic advantage in the form of profit, and increase their market potential. The growth of business performance is influenced by different factors the enterprise can influence, but also a group of factors the businesses cannot influence. However, businesses can carefully prepare for this influence and reduce the negative impact on management and development.

Any market economy must create a satisfactory business environment supporting business activities. The European Union declares that the development of small and medium-sized enterprises, particularly regarding the promotion of family businesses, is a major interest. Economic policy is a tool applied to create a favourable climate for the development of the business activity. In the Western countries of Europe and many other countries of the world (e.g. the USA, Japan), family businesses have a long tradition, and many small-sized family businesses have been transformed into bigger companies. In this respect, Central Europe and Slovakia, in particular, have a long way to go to create suitable conditions, especially for family business development.

Although family businesses have been present in Slovakia for over thirty years, the performance and parameters of their activities lack behind their foreign rivals. They lack sufficient experience with the 


\section{INTERNATIONAL JOURNAL OF ENTREPRENEURIAL KNOWLEDGE}

Issue 2, volume 9, ISSN 2336-2960 (Online)

www.ijek.org

genuine family business, face difficulties with the generational exchange, and take over the family business by the younger generation. The definition of the family business in Slovak legislation is still absent, and no specific conditions were created for development in relation to their specific character. Thanks to globalisation, entrepreneurship is changing not only for small and medium-sized enterprises but also for family businesses. Family enterprises had to adapt to substantial changes not only at regional and national levels but also in transnational terms. The newly created conditions and the advancing globalisation force family businesses to expand their activities on international markets. The domestic environment is no longer satisfying to attract new customers. The need for higher company performance addresses the management to find new solutions. These facts are behind the ever-increasing interest of family businesses entering the international business environment.

Business in an international environment has long been associated with the activity of large enterprises and multinational companies. However, business practice shows sufficient opportunity for smaller market players interested in operating in an international environment. The global tendencies in the form of globalisation trends and the increasing internationalisation into different spheres of our life cannot be avoided. This brings new challenges for business management and the need for an innovative business concept in order to maintain and develop in the market.

International entrepreneurship is a good opportunity for businesses. However, the management or business owners need to be aware of the increased business risk connected to expansion, financial and exchange rate differences, regional specificities, etc. Therefore, a thorough assessment of the benefits and risks arising from the penetration of foreign markets is strictly desirable before the decision to internationalise the business. From the research perspective on family business set by us, it is necessary to address why family businesses decide to penetrate international markets and operate in an international business environment. Business entities may have different incentives. Research in the field of motivation to internationalize family businesses in Slovak conditions is not one of them adequately addressed thematic areas of research. The study presented has the ambition to contribute to a broader elaboration of this issue.

\section{THEORETICAL BACKGROUND}

The main motivation to start family business is self-realization of all participating family members running the business. The biggest benefit of family businesses is the possibility to create employment and income for family members. The leading motive typical of family businesses is to satisfy mainly the social and economic needs of family members. The entrepreneurship in form of family businesses in Slovakia has not yet reached the stage, where these types of businesses would be significantly established nationwide. Their activity is visible regionally. Family businesses operate in different regions of Slovakia and have different level of economic, social development and infrastructure. They have become active players of the regional economy.

Both the Slovak and the European legislation defines the freedom to conduct business. Srebalova et al. (2020) focused on mapping and comparing the legislation with particular regard to start-up businesses. The evaluation is focusing on the specification and general conditions of businesses conducted by natural persons and legal entities. It is also addressing some specific conditions in the field of start-up of business activities. All these legal frameworks represent an absolute legal basis for potential entrepreneurs to operate. The obstacles to entrepreneurship are presented in form of analysis that is related to legislative problems. The team of authors formulates several recommendations we identify with e.g. the concept of family business is not adequately defined by the Slovak law.

Srebalova et al. (2020) focus on entrepreneurship in domestic environment defined in the Slovak legal system. However, the situation is different in cases where business is considering international expansion. 


\section{INTERNATIONAL JOURNAL OF ENTREPRENEURIAL KNOWLEDGE}

Issue 2, volume 9, ISSN 2336-2960 (Online)

www.ijek.org

More and more businesses are considering other growth opportunities than it is provided by the domestic business environment. The lack of market opportunities, closer scope for development are just one of the motives we will address in the next part of the study. If the family business decides to conduct international activity, it is advisable that the owners, family members working in the enterprise become acquainted with the basic theoretical hints highlighted by Buckley \& Casson (2019). These are, above all, the boundaries of a multinational enterprise, the external environment of an enterprise and its internal structure. Before making a decision to penetrate international markets, essential step is the analysis of the internal corporate structure and the external environment as well. The external environment is characterized by competitors. Each enterprise has its own business motives and based on a different decision-making model. All attributes need to be integrated into decision-making.

Entering the international environment is influenced by many factors. One of them is certainly the presence of global trends and the movement of goods, services, capital, human resources on a global scale. According to Dubravska \& Sira (2015), this presents a new major challenge not only for specific national economies, but also for the enterprises themselves. The expansion of globalisation and the associated internationalisation are currently the most obvious characteristics in international business and in the world economy. Globalisation has completely transformed the competitive rivalry not only locally, regionally, but also transnationally and globally. The search for optima involves a global strategy in which globalisation and local adaptation to local conditions are present. Globalisation has thus become a leading phenomenon determining international entrepreneurship. Slovakia is in a strategic position in the middle of Europe, which provides an opportunity to become a popular region in international context.

Similarly, Patel et al. (2012) emphasize that adoption to globalisation process is a strategic choice for family businesses. However, it has to be highlighted that global strategies are not standard for small and medium-sized enterprises, where family businesses are mostly included. It is therefore necessary to detect the catalysts of family businesses entering the global markets. These trends can both strengthen and weaken the position of family enterprises and their expansion on global markets. Mach et al. (2018) or Dubravska \& Marchevska (2019) addressed to identify the impact of globalisation pressure on selected Slovak companies. They followed the companies at the stage of internationalization of their business activities. They focused on finding motives for food industry leaders to enter foreign markets and the motive behind their move as well. In their case, the lack of subcontractors on the domestic market, and the success of competitors in international business were responsible for the internationalisation of the business. The authors' research also focused on larger businesses, not on micro and small or family businesses. Srebalová \& Vojtech (2021) drew attention to the analysis of enterprises from the small and medium-sized enterprises sector in order to estimate the selected indicators.

Based on foreign literary sources, it is possible to observe the efforts of family businesses to internationalize their activities. In the case of family forms of business, the internationalisation of entrepreneurship becomes significant, as it brings the opportunity to operate in an international environment and become competitive. Ahamat el al. (2017) examined the strategy of family business in the UAE in the field of internationalization, and compared it with cases from other countries. The overview is mainly about the strategies applied by family businesses in the Middle East. The research sample of family businesses relies on joint ventures, acquisitions, exports, $100 \%$ subsidiaries and franchise strategies for internationalisation. This is an interesting finding as FSD or other countries are doomed by foreign direct investment, mergers and acquisitions.

Ivanova et al. (2015) tried to process a review article specifically aimed at internationalizing the business activities of family businesses. They found a number of important attributes of the internationalisation of family business. According to the team of authors, the issue of examining the internationalisation of small and medium-sized family businesses has not been addressed adequately. Rapid growth is 


\section{INTERNATIONAL JOURNAL OF ENTREPRENEURIAL KNOWLEDGE}

Issue 2, volume 9, ISSN 2336-2960 (Online)

www.ijek.org

particularly characteristic for the most recently evaluated period. In addition to theory of internationalization, the theory of ownership administration was applied. Significant findings can be detected in comparison of family and non-family businesses. The ownership and management figure as negative factors in the internationalisation process.

One of the well-known Slovak scientists, Lesakova (2010) mapped the internationalization approach of the small and medium-sized business sector, especially the impact of leaders' experience on the decision to enter the international business environment. Decision-making maps in strategies play an important role in identifying the foreign markets.

Rexhepi et al. (2017) recommend the selection and creation of a business model as a basis for an internationalization strategy for family business. It is actually a new conceptual model. The model is based on three stages: domestic performance and preparation for the foreign market, choosing the right model of internationalisation, and choosing the right business strategy depending on the size of the family business. There are several reasons behind the international expansion of family businesses in the form of internationalisation. (Ali \& Ahamat ,2018).

Ratten \& Tajeddini (2017) decided to reveal the opportunities that internationalisation brings for family forms of business. The authors say that the internationalization of family business encourages innovation as they have a good reputation among customers. According to the authors, the ability to be an innovative family business depends on the ability of the company to meet the customer need in an international environment and accepting a measure of international business risk. Family businesses introducing several innovations have a higher chance of penetrating foreign markets. The team of authors led by Daneshjo et al. (2018) also support business growth generated by innovation. The management is assigned the task of effectively coordinating business processes and specificities in order to ensure innovation.

Spisakova (2010) also expresses support for innovation, especially in the period of economic recession, since innovation is a prerequisite for survival in a strong competitive struggle. Innovation can become an active tool against the obstacles of entrepreneurship, especially in the small and medium-sized business sector. Innovation helps smaller businesses overcome business barriers, which is reflected by Civelek et al. (2021). It is innovation that can actively help SMEs in a global environment (Ključnikov et al., 2021). Innovation needs investment, too (Kotaskova et al., 2020). Thanks to successfully introduced innovations and a successful competitive position, several family businesses are becoming economically successful and powerful market units. The authors hope that the practices implemented by successful multinational family businesses will be a model for other family businesses (Rumanko et al., 2021).

\section{AIMS, METHODOLOGY , AND METHODS}

The submitted study is based on the need to explore the field of international entrepreneurship and the phenomenon of internationalization of Slovak family enterprises. The issue is not adequately addressed in the in Slovak business environment, although the topic is extremely important and the knowledge of business practice needs to be properly evaluated. Family businesses have numerous specificities, which can also be reflected in the internationalisation of their business. The nature of the enterprise is different from non-family forms of business, the management and decision-making process is again different from non-family enterprises. The motives that lead businesses to internationalise their business may vary. These were the main issues we were trying to address. This survey is part of broader scientific research and research in the small and medium-sized business sector with a focus on family business. Research activity is part of the solution of the current two research grants: GAAA 5-5/2020 - Development of family businesses in Slovak regions, which has received funding from Grant Agency Academia Aurea, and project VEGA 1/0813/19 - Managing the development of innovative and start-up forms of 


\section{INTERNATIONAL JOURNAL OF ENTREPRENEURIAL KNOWLEDGE}

Issue 2, volume 9, ISSN 2336-2960 (Online)

www.ijek.org

businesses in international environment and verification of INMARK concept, which has received funding from the Ministry of Education, Science, Research and Sport of the Slovak Republic.

The aim of this study is to identify the current trend of international business activity of family enterprises. The partial objectives are the following:

examine the motives why business decide to operate in an international business environment examine the territorial scope of those family businesses that have chosen to operate in an international business environment.

The scientific study is based on two pillars: The theoretical pillar of the study explains entrepreneurship, family entrepreneurship, internationalisation and the motives of family businesses to enter international markets. The theoretical approach of this is study is based on published studies from foreign and Slovak authors. We have put emphasis on using literary resources of international databases, Web of Science and Scopus. We classify these as secondary resources to this study. In addition, it served as a prerequisite to conduct the research. The primary data of this research were obtained from family businesses operating in selected regions of Slovakia, where partial stage of research projects focused on small and medium-sized enterprises and their development in the selected Slovak regions. Four self-governing regions were involved: Bratislava Region, Trnava Region, Nitra Region and Trenčín Region. 60 enterprises from each self-governing region were selected, characterized as family enterprises. 177 out of 240 addressed business entities showed willingness to cooperate in the research. We obtained not fully completed questionnaires, which were excluded from the analysis of the obtained data. Altogether 21 completed questionnaires were not used in data analysis, since the results would not be transparent. The research sample at this stage consisted of 156 family enterprises.

The main areas surveyed by the questionnaire technique were the following: the identification of motives why family businesses decided to enter international markets. The second important area we tried to map was the territorial interest of family businesses to penetrate foreign markets.

The methodological approach of the research was mixed due to the nature of the topic being studied. Qualitative methods helped us understand the behavior of family businesses (observation, interviews). Quantitative methods allowed us to collect data and conduct a deeper analysis of the data obtained. Questionnaire survey, testing, hypothesis testing and cluster analysis were used as quantitative methods. When testing hypotheses, zero hypothesis was formulated.

\section{RESULTS AND DISCUSSION}

Chi-square test, t-test and clump analysis were applied to test the research hypotheses.

Chi-square test is one of the most often used statistical methods to test statistical hypotheses. It should be noted that in the case of validity of the zero hypothesis, the test criterion has a Chi-square distribution. In mathematical statistics, the tests are calculated directly using so-called p-values. The presentation of the p-value is similar to that of another statistical test. Furthermore, in statistical procedures and calculations, we relied on the Student's t-test, which is conducted in order to determine the possible origin of two samples from two basic files with the same average value. Finally, a cluster analysis was applied. Cluster analysis is a form of clustering, i.e. grouping the items according to certain common features. The primary role of cluster analysis is to break down a set of items into several relatively homogenous subsets. In our case, we chose cluster analysis to identify the common features and similarities of the target markets the family businesses would like to penetrate. A great advantage of cluster analysis is also the possibility of graphical presentation in form of dendrogram. In our research, the Ward's method was used, which helps to organize the target markets (individual states). 


\section{INTERNATIONAL JOURNAL OF ENTREPRENEURIAL KNOWLEDGE}

Issue 2, volume 9, ISSN 2336-2960 (Online)

www.ijek.org

We formulated the following hypotheses:

H1: More than balf of the family businesses surveyed would prefer to enter an international business environment they prefer instead of the domestic environment.

Using the Chi-square test, we examined the relationship of the respondents in relation to entering the international business environment. We formulated the relevant hypotheses and quantified the p-value for our monitored set. We conducted our research at a significance level of $5 \%$. The p-value was 0.6235 , which was compared to the level of significance. It is clear from the above comparison that Hypothesis $\mathrm{H}_{0}$ is approved. It means that the family businesses do not enter the international environment in a targeted way. Practically, penetration of international markets of the companies participating in the research is random and not planned activity.

The next hypothesis was set as the following:

H2: There is a difference in the perception of motivation entering international markets among the surveyed businesses.

Hypothesis $\mathrm{H} 2$ addressed the partial issue of motivation, why family business are interested in internationalization of their entrepreneurial activity. We identified some factors why businesses decide on internationalization. The surveyed family business were divided into two groups, those already operating on international markets, and those that have not had an experience with entering foreign markets. A t-test was applied for statistical analysis at a significance level of $5 \%$. The zero hypothesis is set as there is no difference in terms of motivation to internationalise among the preferred enterprises. 112 enterprises from 156 included in the survey has already had experience with the international business environment. Based on the calculations made by statistical software, the results are presented in Table 1.

Table 1 Quantification of t-tests

\begin{tabular}{|l|r|r|r|r|r|r|}
\hline Method & Mean & $95 \%$ CL Mean & Std Dev & 95\% CL Std Dev \\
\hline & 2.4464 & 2.2878 & 2.6051 & 0.8472 & 0.7489 & 0.9755 \\
\hline & 2.1333 & 1.7217 & 2.5449 & 0.7432 & 0.5441 & 1.1721 \\
\hline Pooled & 0.3131 & -0.1419 & 0.7681 & 0.8362 & 0.7442 & 0.9545 \\
\hline Satterthwaite & 0.3131 & -0.1218 & 0.7480 & & & \\
\hline
\end{tabular}

\begin{tabular}{|l|l|r|r|r|}
\hline Method & Variances & DF & t Value & $\operatorname{Pr}>|t| t \mid$ \\
\hline Pooled & Equal & 125 & 1.36 & 0.0048 \\
\hline Satterthwaite & Unequal & 19.224 & 1.51 & 0.0065 \\
\hline
\end{tabular}

\begin{tabular}{|l|r|r|r|r|}
\hline \multicolumn{4}{|c|}{ Equality of Variances } \\
\hline Method & Num DF & Den DF & F Value & Pr > F \\
\hline Folded F & 111 & 14 & 1.30 & 0.6009 \\
\hline
\end{tabular}

(Source: own calculations)

Based on the calculated values presented, we can conclude that there is a significant difference in terms of motivation of the surveyed enterprises to internationalise their activities. Enterprises that have already established themselves on foreign markets have different motivating factors to do business internationally than those who have not entered foreign markets yet. 


\section{INTERNATIONAL JOURNAL OF ENTREPRENEURIAL KNOWLEDGE}

Issue 2, volume 9, ISSN 2336-2960 (Online)

www.ijek.org

As the last in-depth statistical analysis, a cluster analysis was chosen. The Ward's method was used for our analysis, and the obtained results are presented in form of a hierarchical graph. This clustering method is called the method of minimum variance. This means that it minimizes the increase the amount of square deviation items from their centroids.

\section{Figure 1 Cluster analysis - Ward's method}

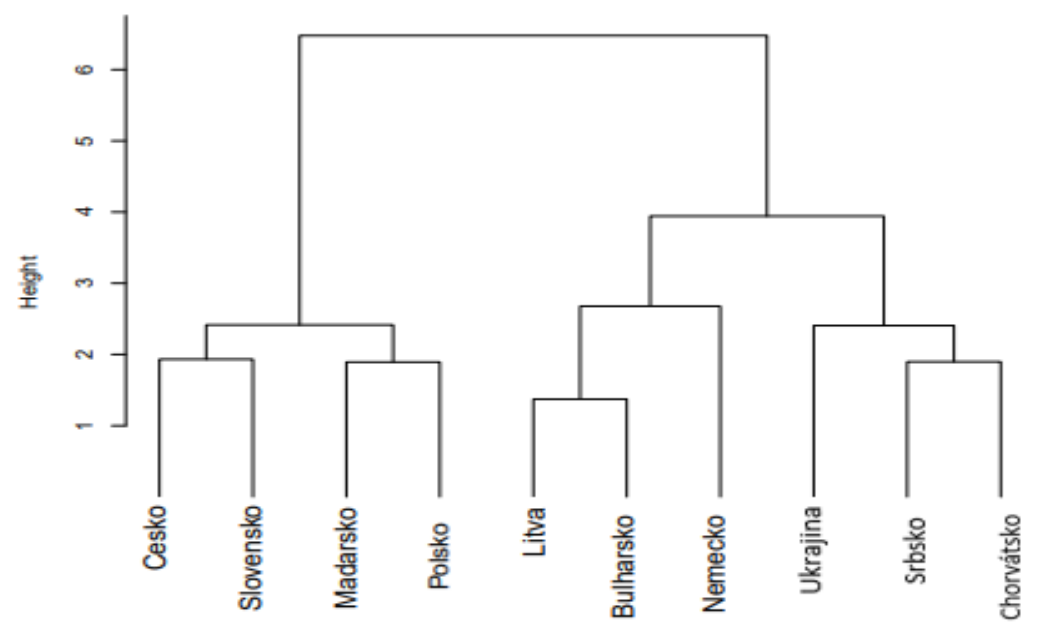

(Source: own calculations)

Figure 1 shows the dendogram obtained by applying the Ward's method. The output is the division of states into two clusters. The first cluster is made up of target markets that concern the Visegrad Four states. Family businesses find better opportunities entering these markets than operating on domestic markets. It is important to emphasize that the closest foreign market for companies is the Czech Republic. The second group in the first cluster is formed by the markets of Hungary and Poland. Slovak companies are close to these target markets. It can be explained by the similar culture, history and consumer preferences. The language barrier is not significant as well. The second cluster is formed by distant target markets for family businesses. In the second cluster, we can see smaller subgroups again. One of them consists of the states of the former Yugoslavia, e.g. Serbia and Croatia, joined by Ukraine. These markets have no significant language barriers. The Slavic culture and consumer behaviour are similar. Successful family businesses were able to penetrate also the more competitive market of Lithuania and western Germany. This speaks about the high quality of the products of these businesses. These international business activities help family businesses not only gain better value for their investment, but also grow on the foreign market they entered. They have an opportunity to increase their competitiveness as well. Diversification undoubtedly helps family businesses not only survive, but also grow in a turbulent and competitive business environment.

\section{CONCLUSIONS}

Entrepreneurship in the 21st century is influenced by different factors, regional, national, and global factors, which have a relevant impact on the national economy and the enterprises themselves. We are increasingly observing the impact of globalisation and widening internationalization on macro and microeconomic levels. The international economic cooperation emerging between all economic players, 


\section{INTERNATIONAL JOURNAL OF ENTREPRENEURIAL KNOWLEDGE}

Issue 2, volume 9, ISSN 2336-2960 (Online)

www.ijek.org

organisations, institutions, and states is subject to numerous dynamic changes. These directly change the conditions for conducting business activities. Today, large and multinational companies and other groups of businesses enter the international business environment. These include family businesses, which are also trying to seek new markets for their products and activities beyond the domestic boundaries.

There is not an adequate number of published studies related to the international activity of family enterprises in general. The number of studies published about the internationalization activity of Slovak family enterprises stays at the minimum. This was also one of the motives for examining the current situation in this field. This study aimed to identify the current trend in the international business activity of family enterprises in terms of their territorial activity. Partial objectives were to examine the motives why companies decide to enter the international business environment. Based on the survey results in selected regions of Slovakia, we can conclude that international entrepreneurship is becoming an active phenomenon among small and medium-sized family businesses. However, we cannot discuss targeted activity based on the researched sample. It is more likely a random decision triggered by specific incentives. A hidden incentive behind entering international markets is the opportunity to expand the activity on new markets. We also examined whether the family businesses in our sample penetrated the nearest markets, i.e., the Visegrad Four markets, or went beyond the borders of V4 group. Based on the hypothesis verification, we can conclude that Slovak family enterprises penetrate the markets beyond the V4 group's borders. This means that in addition to Poland, the Czech Republic, and Hungary, these companies are also trying to establish themselves in other markets. The markets of former postcommunist countries dominate, most often Ukraine, Bulgaria, Croatia, Serbia, Lithuania, but also Germany, for example. In the future, it is possible to anticipate a stronger interest in developing the international business activities of Slovak family businesses to improve their market position, increase their performance, and boost their competitiveness.

\section{ACKNOWLEDGEMENT}

The paper was supported by the projects: GAAA 5-5/2020 Development of family businesses in Slovak regions, which has received funding from Grant Agency Academia aurea and project VEGA 1/0813/19 Managing the development of innovative and start-up forms of businesses in international environment and verification of INMARK concept, which has received funding from the Ministry of Education, Science, Research and Sport of the Slovak Republic.

\section{REFERENCES}

Ahamat, A., Dirir, A. Y., \& Robani, A. (2017). International business expansion strategy: The review of UAE family business. Proceedings of mechanical engineering research day 2017 (MERD), 276-278

Ali, M. S. S., \& Ahamat, A. (2018). Internationalization process of firms from developing country: an empirical evidence of uae family business firms. 5th International Conference on Education and Social Sciences (INTCESS 2018), 672-679

Buckley, P., \& Casson, M. (2019). Decision-making in international business. Journal of International Business Studies, 50 (8), SI, 1424-1439. https://doi.org/10.1057/s41267-019-00244-6

Civelek, M., Ključnikov, A., Fialova, V., Folvarčná, A., \& Stoch, M. (2021). How innovativeness of familyowned SMEs differ depending on their characteristics?. Equilibrium. Quarterly Journal of Economics and Economic Policy, 16(2), 413-428. https://doi.org/10.24136/eq.2021.015

Daneshjo, N., Lieskovska, V., \& Pajerska, ED. (2018). Strategy and strategic management in business development. 12th International days of statistics and economics, 307-316.

Dubravska, M., \& Marchevska, M. (2019). Acceptance of Internationalization as a Current Trend in A Globalizing World: Case Study of Slovak Food Industry. 34th International-Business-Information- 
INTERNATIONAL JOURNAL OF ENTREPRENEURIAL KNOWLEDGE

Issue 2, volume 9, ISSN 2336-2960 (Online)

www.ijek.org

Management-Association (IBIMA) Conference. VISION 2025: Education excellence and management of innovations through sustainable economic competitive advantage, 13346-13351

Dubravska, M., \& Sira, E. (2015). The Analysis of The Factors Influencing The International Trade of The Slovak Republic. Procedia Economics and Finance, 23, 1210-1216. https:/ /doi.org/10.1016/S22125671(15)00569-9

Ivanova, Y. V., Dentchev, N., \& Todorov, K. A. (2015). Family Business Internationalization in the New Millennium: Achievements and Avenues for Future Research? International review of entrepreneurship, 13 (4), 291-323

Ključnikov, A., Civelek, M., Fialova, V., \& Folvarčná, A. (2021). Organizational, local, and global innovativeness of family-owned SMEs depending on firm-individual level characteristics: evidence from the Czech Republic. Equilibrium. Quarterly Journal of Economics and Economic Policy, 16(1), 169184. https://doi.org/10.24136/eq.2021.006

Kotaskova, A., Lazanyi, K., Amoah, J., \& Belas, J. (2020). Financial risk management in the V4 Countries' SMEs segment. Investment Management and Financial Innovations, 17(4), pp. 228-240. https://doi.org/10.21511/imfi.17(4).2020.21

Lesakova, D. (2010). Managerial Decision in the Internationalization of Small and Medium Businesses. Ekonomicky casopis, 58 (10), 1026-1038

Mach, J., Dvořák, M., \& Hošková, P. (2018). EU Milk and Dairy Market Changes and Impact of Globalisation Trends. 18th International Scientific Conference. Globalization and its socio-economic consequences (Part III.- Economic Progress in Post-Soviet Countries), 1204 - 1212

Patel, V. K., Pieper, T. M., \& Hair, J. F., Jr. (2012). The global family business: Challenges and drivers for cross-border growth. Business Horizons, 55 (3), SI, 231-239. https://doi.org/10.1016/j.bushor.2012.01.002

Ratten, V., \& Tajeddini, K. (2017). Innovativeness in family firms: an internationalization approach. Review of International Business and Strategy, 27 (2), 217-230. https://doi.org/10.1108/RIBS-12-20160085

Rexhepi, G., Ramadani, V., Rahdari, A., \& Anggadwita, G. (2017). Models and strategies of family businesses internationalization A conceptual framework and future research directions. Review of International Business and Strategy, 27 (2), 248-260. https://doi.org/10.1108/RIBS-12-2016-0081

Rumanko, B., Kozáková, J., Urbánová, M., \& Hudáková, M. (2021). Family business as a bearer of social sustainability in multinationals-case of Slovakia. Sustainability, 13 (14), 7747. https://doi.org/10.3390/su13147747

Spisakova, E. (2010). Analysis of innovation activity of Slovak and Czech enterprises. Quality Innovation Prosperity-Kvalita Inovacia Prosperita, 14 (1-2), 42-56. https://doi.org/10.12776/qip.v14i1-2.33

Srebalová, M. \& Vojtech, F. (2021). SME Development in the Visegrad Area. Eurasian Studies in Business and Economics, 17, 269-281. https://doi.org/10.1007/978-3-030-65147-3_19

Srebalova, M., Horvath, M., Vacok J., Vojtech F., \& Filip, S. (2020). Legal obstacles to freedom to conduct a business: experience of the Slovak Republic. Entrepreneurship and Sustainability Issues, 7(4), 3385-3394. https://doi.org/10.9770/jesi.2020.7.4(53)

\section{BRIEF DESCRIPTION OF AUTHOR:}

Assoc. Prof. PhDr. Ing. Ladislav Mura, PhD., MSc.

ORCID: https://orcid.org/0000-0002-2453-8740

Department of International Entrepreneurship, Faculty of Economics and Business, Pan-European University in Bratislava, Tematínska 10, 85105 Bratislava, Slovakia, Affiliation web page: www.paneurouni.com, email: ladislav.mura@gmail.com. He is head of the Department of International Entrepreneurship. His research is focused on Small and Medium Enterprises, Family Business, 
INTERNATIONAL JOURNAL OF ENTREPRENEURIAL KNOWLEDGE

Issue 2, volume 9, ISSN 2336-2960 (Online)

www.ijek.org

International Entrepreneurship, Business Environment, and Human Resource Management. In addition, he is a supervisor for master and doctoral students as well as an author of a number of national and international journal articles. 